\title{
Influence of Mn substitution on crystal structure and magnetocrystalline anisotropy of nanocrystalline $\mathrm{Co}_{1-x} \mathrm{Mn}_{x} \mathrm{Fe}_{2-2 x} \mathrm{Mn}_{2 x} \mathrm{O}_{4}$
}

\author{
Lawrence Kumar • Pawan Kumar • \\ Manoranjan Kar
}

Received: 5 February 2012/ Accepted: 18 February 2012/Published online: 8 March 2012

(c) The Author(s) 2012. This article is published with open access at Springerlink.com

\begin{abstract}
Nanocrystalline $\mathrm{Mn}$ substituted cobalt ferrite $\mathrm{Co}_{1-x} \mathrm{Mn}_{x} \mathrm{Fe}_{2-2 x} \mathrm{Mn}_{2 x} \mathrm{O}_{4}(x=0.0-0.4)$ has been synthesized by the standard citrate-gel method. The structural and magnetic characteristics of all samples have been studied using powder X-ray diffraction, Fourier transform infrared spectroscopy (FT-IR), field emission scanning electron microscope (FE-SEM) and VSM techniques. Distributions of cations between the two interstitial sites (tetrahedral and octahedral site) have been estimated qualitatively by analyzing the powder X-ray diffraction patterns by employing the Rietveld refinement technique. All samples are found to be mixed spinel with cubic structure ( $F d \overline{3} m$ space group). The FT-IR study shows the presence of absorption bands in the range of 390$750 \mathrm{~cm}^{-1}$, which confirm the spinel structure of the sample. The stoichiometry of $\mathrm{Co}, \mathrm{Fe}, \mathrm{Mn}$ and $\mathrm{O}$ ions in the sample has been obtained by using energy-dispersive spectrum with help of an FE-SEM. The magnetizations in saturation have been analyzed by employing the "law of approach" technique. The saturation magnetization, coercivity and magnetocrystalline anisotropy constant depend upon $\mathrm{Mn}$ ion concentration and crystallite size.
\end{abstract}

Keywords Rietveld - Spinel - Magnetocrystalline · Law of approach $\cdot$ XRD

L. Kumar · P. Kumar · M. Kar ( $₫)$

Department of Physics, Indian Institute of Technology Patna,

Patna 800013, India

e-mail: mano@iitp.ac.in

L. Kumar

Centre for Nanotechnology, Central University of Jharkhand,

Ranchi 835205, India

\section{Introduction}

Ferrimagnetic spinel cobalt ferrite $\left(\mathrm{CoFe}_{2} \mathrm{O}_{4}\right)$ belongs to important class of magnetic ceramic oxides which crystallizes to mixed spinel structure and, it is represented by a general molecular formula $\left(\mathrm{Co}_{x}^{2+} \mathrm{Fe}_{1-x}^{3+}\right)_{\text {tetra }}\left[\mathrm{Co}_{1-x}^{2+}\right.$ $\left.\mathrm{Fe}_{1+x}^{3+}\right]_{\text {octa }} \mathrm{O}_{4}$, where ' $x$ ' depends upon heat treatment and preparation conditions (Haneda and Morrish 1988). The unit cell of its crystal structure consists of cubic closedpack arrangement of oxygen ions with 64 tetrahedral (A-sites) and 32 octahedral sites (B-sites). However, only eight tetrahedral and 16 octahedral sites are occupied by metal cations (Cullity 2009). Thus, the large fraction of empty interstitial sites makes a considerable open crystal structure conducive to cation migration. The magnetic behavior in this ferrite depends on the competition among various kinds of superexchange interactions between $\mathrm{A}$-site and $\mathrm{B}$-site cations, i.e., $\mathrm{Fe}^{3+}(\mathrm{B})-\mathrm{O}-\mathrm{Fe}^{3+}(\mathrm{B}), \mathrm{Fe}^{3+}(\mathrm{B})-\mathrm{O}-$ $\mathrm{Co}^{3+}(\mathrm{B}), \mathrm{Fe}^{3+}(\mathrm{B})-\mathrm{O}-\mathrm{Fe}^{2+}(\mathrm{A}), \mathrm{Co}^{3+}(\mathrm{B})-\mathrm{O}-\mathrm{Fe}^{2+}(\mathrm{A})$ and $\mathrm{Co}^{2+}(\mathrm{A})-\mathrm{O}-\mathrm{Fe}^{3+}(\mathrm{B})$ (Bhowmik et al. 2003). Since the $\mathrm{Co}^{2+}$ ion is highly anisotropic, the strength of superexchange interaction is varied with different occupancies of $\mathrm{Co}^{2+/ 3+}$ ions in A and B sites (Chinnasamy et al. 2001). It has received considerable attention due to its interesting magnetic properties such as high magnetic ordering temperature (around $520^{\circ} \mathrm{C}$ ), moderate saturation magnetization, and high magnetic coercivity. In addition, it exhibits good mechanical hardness and chemical stability. These materials are well known to exhibit high cubic magnetocrystalline anisotropy $\left(K_{1}\right)$ which is a typical feature of the hard magnets (Valenzuela 1994). For instance the cubic magnetocrystalline anisotropy $\left(K_{1}\right)$ of cobalt ferrite of crystallite size about 42 and $35 \mathrm{~nm}$ at room temperature are found to be $3.90 \times 10^{6}$ and $2.27 \times 10^{6} \mathrm{erg} / \mathrm{cm}^{3}$, respectively (Franco and Silva 2010; Kumar and Kar 2011a). 
Nanocrystalline form of this material can be used for technological applications such as microwave devices, magnetic fluids, high-density information storage devices, etc. (Goldman 2006). However, according to our knowledge, information about physical parameters of nanocrystalline cobalt ferrite is not adequate until date to explore its technological applications.

Magnetic properties of bulk materials are solely determined by the cations distribution among the tetrahedral (A) and octahedral (B) sites and these cations show strong preference for particular sites. However, in case of nanocrystalline form, the distribution of cations between the A and B sites is entirely different from the bulk one. The cation distribution profile itself is not enough to determine the physical properties of nanocrystalline material. Surface effects become extremely important as the surface-to-volume ratio increases with the reduction in particle size (Jacob and Khadar 2010). Therefore, the understanding of the nanoparticle surface properties and the cation distribution profile are the key issue as far as the technological applications is concerned. However, to distribute the cations among the $\mathrm{A}$ and $\mathrm{B}$ sites in controlled manner is still a challenging problem. Substitution of various cations (Al, $\mathrm{Mo}, \mathrm{Zn}$ etc.) at the Co site as well as $\mathrm{Fe}$ site of $\mathrm{CoFe}_{2} \mathrm{O}_{4}$ have been studied by several groups to tune the cation distribution among $\mathrm{A}$ and $\mathrm{B}$ sites which leads to tune the magnetic properties (Kumar and Kar 2011b; Dwivedi et al. 2010; Jadhav et al. 2010). The structural and magnetic properties of $\mathrm{Mn}$ ion substituted (in place of $\mathrm{Co}$ or $\mathrm{Fe}$ ) nanocrystalline cobalt ferrite have been reported by various groups. Shobana et al. (2009) have synthesized $\mathrm{Co}_{1-x} \mathrm{Mn}_{x} \mathrm{Fe}_{2} \mathrm{O}_{4}$ by sol gel combustion method and observed that particle size and saturation magnetization decrease with the Mn concentration. Kambale et al. (2010) have prepared $\mathrm{Co}_{1-x} \mathrm{Mn}_{x} \mathrm{Fe}_{2} \mathrm{O}_{4}$ by combustion route and reported that the lattice constant and coercivity increase with the Mn concentration whereas, the saturation magnetization initially increases, then it decrease. Lu et al. (2009) have synthesized $\mathrm{Co}_{0.8} \mathrm{Mn}_{x} \mathrm{Fe}_{2.2-x} \mathrm{O}_{4}$ by sol gel process and showed that the saturation magnetization and coercivity decrease with increase of Mn concentration. Melikhov et al. (2006) have studied the magnetic properties of $\mathrm{CoMn}_{x} \mathrm{Fe}_{2-x} \mathrm{O}_{4}$ and observed that saturation magnetization and cubic magnetocrystalline anisotropy decreases with the Mn concentration. Mn has the advantage to be substituted in both places ( $\mathrm{Co}$ and $\mathrm{Fe}$ ) because it exhibits +2 and +3 valence states, which prefer to enter into tetrahedral and octahedral sites, respectively. However, according to our knowledge, there are no reports on nanocrystalline $\mathrm{Co}_{1-x} \mathrm{Mn}_{x} \mathrm{Fe}_{2-2 x} \mathrm{Mn}_{2 x} \mathrm{O}_{4}$. Here we have synthesized $\mathrm{Mn}$ substituted nanocrystalline cobalt ferrite material having empirical formula $\mathrm{Co}_{1-x} \mathrm{Mn}_{x} \mathrm{Fe}_{2-2 x}$ $\mathrm{Mn}_{2 x} \mathrm{O}_{4}(x=0.1,0.2,0.3$ and 0.4$)$ by standard citrate-gel method. As the Mn ion exists in +2 and +3 states, one may able to tune the physical properties of spinel cobalt ferrite by substituting the $\mathrm{Mn}$ ion at both $\mathrm{Co}$ site and $\mathrm{Fe}$ site in $\mathrm{CoFe}_{2} \mathrm{O}_{4}$. Here we have reported detailed crystal structure and size dependent cubic magnetocrystalline anisotropy at room temperature of nanocrystalline $\mathrm{Co}_{1-x} \mathrm{Mn}_{x} \mathrm{Fe}_{2-2 x}$ $\mathrm{Mn}_{2 x} \mathrm{O}_{4}(x=0.1,0.2,0.3$ and 0.4$)$ samples. Physical properties of parent compound $\mathrm{CoFe}_{2} \mathrm{O}_{4}(x=0.0)$ have been reported in our recent publication (Kumar and Kar 2011a). Hence, we have not included any data in this paper for the sample $\mathrm{CoFe}_{2} \mathrm{O}_{4}$. However, we have referred the data for conclusions.

\section{Experimental techniques}

Nanocrystalline $\mathrm{Co}_{1-x} \mathrm{Mn}_{x} \mathrm{Fe}_{2-2 x} \mathrm{Mn}_{2 x} \mathrm{O}_{4}(x=0.1,0.2,0.3$ and 0.4) materials were prepared by the citrate-gel method. Cobalt nitrate $\left[\mathrm{Co}\left(\mathrm{NO}_{3}\right)_{2} \cdot 6 \mathrm{H}_{2} \mathrm{O}\right]$, iron nitrate $\left[\mathrm{Fe}\left(\mathrm{NO}_{3}\right)_{3}\right.$. $\left.9 \mathrm{H}_{2} \mathrm{O}\right]$, manganese acetate $\left[\left(\mathrm{CH}_{3} \mathrm{COO}\right)_{2} \mathrm{Mn} \cdot 4 \mathrm{H}_{2} \mathrm{O}\right]$ and citric acid $\left(\mathrm{C}_{6} \mathrm{H}_{8} \mathrm{O}_{7} \cdot \mathrm{H}_{2} \mathrm{O}\right)$ with $99.9 \%$ purity were used as starting materials. The molar ratio of metal nitrates to citric acid was taken as 1:3. The metal nitrates were dissolved in a deionized water (milli $\mathrm{Q}$ grade) to get a solution. An aqueous solution of citric acid was mixed with metal nitrates solution. The mixed solution was heated at $80^{\circ} \mathrm{C}$ with constant stirring using hot plate. The solution became viscous and finally forming brown gel. The gel was dried overnight using an oven at $80^{\circ} \mathrm{C}$ in order to remove excess water. During the process of drying, the gel swells into the fluffy mass and eventually broke into brittle flakes. The resulting materials were heat treated in air atmosphere at $600^{\circ} \mathrm{C}$ for $2 \mathrm{~h}$. The crystalline phase of the annealed samples was identified by the powder X-ray diffraction method (Rigaku Miniflex) using $\mathrm{CuK}_{\alpha}$ radiation. Fourier transform infrared spectra (FT-IR) were recorded with a Perkin Elmer (Model Spectrum 400) within the wave number range of $390-1,900 \mathrm{~cm}^{-1}$. The compositions of all the samples were studied by EDS (energy-dispersive spectroscopy) using Hitachi S4800 field emission scanning electron microscope (FE-SEM). The magnetic hysteresis loops were recorded at room temperature $\left(25^{\circ} \mathrm{C}\right)$ by using a LakeShore (Model No. 7410) vibrating sample magnetometer (VSM). The maximum field was used $\pm 1.5 \mathrm{~T}$.

\section{Results and discussion}

The XRD patterns of $\mathrm{Co}_{1-x} \mathrm{Mn}_{x} \mathrm{Fe}_{2-2 x} \mathrm{Mn}_{2 x} \mathrm{O}_{4}(x=0.1,0.2$, 0.3 and 0.4) samples annealed at $600^{\circ} \mathrm{C}$ are shown in Fig. 1 . Samples with $x=0.1,0.2$ and 0.3 are essentially in singlephase form. However, there are some additional peaks along 


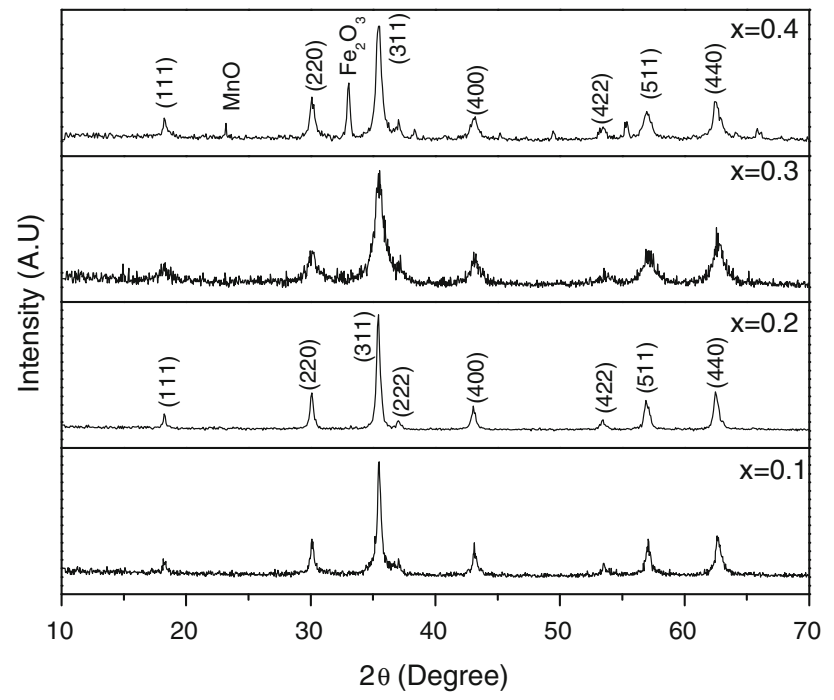

Fig. 1 XRD patterns of the sample $\mathrm{Co}_{1-x} \mathrm{Mn}_{x} \mathrm{Fe}_{2-2 x} \mathrm{Mn}_{2 x} \mathrm{O}_{4}$ $(x=0.1,0.2,0.3$ and 0.4$)$ annealed at $600^{\circ} \mathrm{C}$. The extra peaks observed for the sample $x=0.4$ are identified as $\mathrm{MnO}$ and $\mathrm{Fe}_{2} \mathrm{O}_{3}$ from the ICDD database with no. 00-004-0326 and 01-074-6271, respectively

with $F d \overline{3} \mathrm{~m}$ space group peaks have been observed for $x=0.4$ sample which leads to phase segregation. We have identified that extra peaks are due to the presence of $\mathrm{MnO}$ (PDF4 No. 00-004-0326) and $\mathrm{Fe}_{2} \mathrm{O}_{3}$ (PDF4 No. 01-074-6271) by using ICDD database. It implies that $\mathrm{Mn}$ ions have limited solubility in the solid crystal structure of $\mathrm{CoFe}_{2} \mathrm{O}_{4}$. The XRD peaks for samples with $x \leq 0.3$ could be indexed to $F d \overline{3} m$ space group with cubic symmetry.

All the XRD patterns were analyzed employing the Rietveld technique (Young 1996) with the help of Fullprof Suite 2009 release programme. The patterns for all the samples could be refined using the $F d \overline{3} \mathrm{~m}$ space group. A typical XRD pattern along with Rietveld refinement is shown in Fig. 2 for the sample $\mathrm{Co}_{0.9} \mathrm{Mn}_{0.1} \mathrm{Fe}_{1.8} \mathrm{Mn}_{0.2} \mathrm{O}_{4}$. Here the experimental data are shown as open circles and calculated intensities are shown as solid line. The bottom line represents the difference between measured and calculated intensities. The allowed Bragg's positions for the $F d \overline{3} m$ space group are marked as vertical lines. All the observed peaks are allowed Bragg $2 \theta$ positions. The typical fractional positions of the atoms for the samples $\mathrm{Co}_{0.9} \mathrm{Mn}_{0.1} \mathrm{Fe}_{1.8} \mathrm{Mn}_{0.2} \mathrm{O}_{4}$ are given in Table 1. The oxygen positions $(x=y=z)$ were taken as free parameters during fitting, however, all other atomic fractional positions were taken as fixed. Other parameters such as, lattice constants, isothermal parameters, occupancies, scale factors and shape parameters were taken as free parameters. Background was refined by using pseudo Voigt function.

Various $R$ factors for the samples are listed in Table 2. Values of $R$ factors are found to be large. Similar high

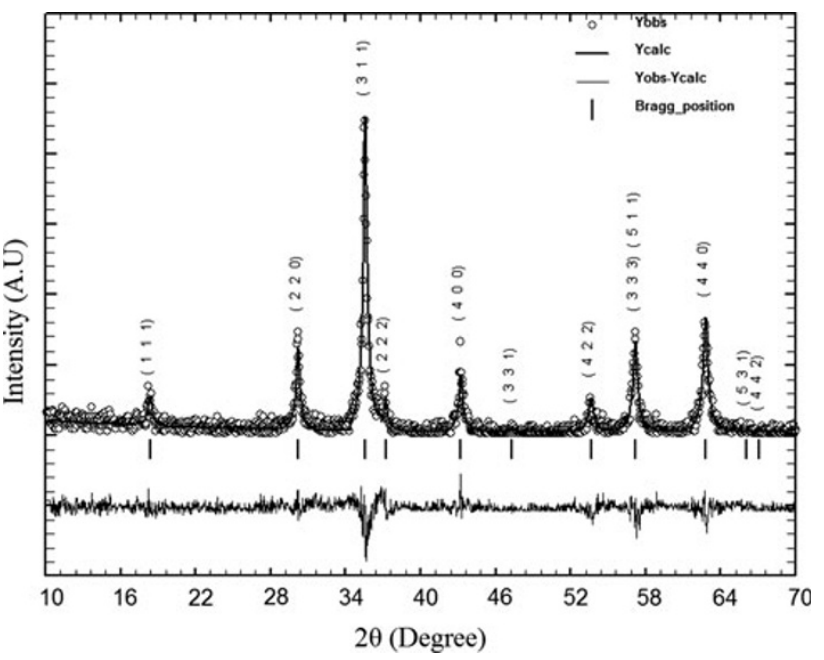

Fig. 2 Rietveld-refined XRD pattern for the sample $\mathrm{Co}_{0.9} \mathrm{Mn}_{0.1}$ $\mathrm{Fe}_{1.8} \mathrm{Mn}_{0.2} \mathrm{O}_{4}$ annealed at $600^{\circ} \mathrm{C}$. The circles represent experimental points and the solid line represents Rietveld-refined data. The bottom line shows the difference between the experimental and refined data. The marked $2 \theta$ positions are the allowed Bragg peaks

Table 1 Typical atomic coordinate $(x, y, z)$ of different atom for the sample $\mathrm{Co}_{0.9} \mathrm{Mn}_{0.1} \mathrm{Fe}_{1.8} \mathrm{Mn}_{0.2} \mathrm{O}_{4}$

\begin{tabular}{llll}
\hline Atoms & $x$ & $y$ & $z$ \\
\hline $\mathrm{Co} / \mathrm{Fe} / \mathrm{Mn}$ & 0.12500 & 0.12500 & 0.12500 \\
$\mathrm{Fe} / \mathrm{Co} / \mathrm{Mn}$ & 0.50000 & 0.50000 & 0.50000 \\
$\mathrm{O}$ & 0.24932 & 0.24932 & 0.24932 \\
\hline
\end{tabular}

values of $R$ factors for nanocrystalline materials have been observed by the other research groups (Abbas et al. 2011; Bhagwat et al. 2003). It could be due to the large noise to signal ratio of XRD patterns for nanocrystalline materials. Diffuse scattering is dominant in the diffraction pattern of nanocrystalline materials compare to that of bulk crystalline materials. It is due to large ratio of surface-to-volume atoms for nanocrystalline materials, which leads to diminish of Bragg scattering. Hence, large reliability factors are observed (Jovic et al. 2009). However, we have observed a low value of $\chi^{2}$ (goodness of fit) in our analysis.

The analysis of the crystallite size has been carried out using the peak broadening of the XRD patterns. Peak broadening comes from several sources such as instrumental effect, finite crystallite size and strain effect within the crystal lattice. The crystallite sizes of the samples have been obtained using the Rietveld method because in the Rietveld method all the instrumental factors are taken into account for the correction of peak broadening. A complete expression used in the Rietveld method (Young 1996) is defined as,

$\mathrm{FWHM}^{2}=\left(U+D_{\mathrm{ST}}^{2}\right)\left(\tan ^{2} \theta\right)+V(\tan \theta)+W+\frac{\mathrm{IG}}{\cos ^{2} \theta}$ 
Table 2 Rietveld agreement factors $\left(R_{\mathrm{p}}=\right.$ profile factor, $R_{\mathrm{Bragg}}=$ Bragg factor, $R_{\mathrm{F}}=$ crystallographic, $R_{\mathrm{F}}$ factor and $\chi^{2}=$ goodness of fit factor), lattice constant $(a)$, average crystallite size $(D)$ and

\begin{tabular}{llllllrr}
\hline Sample & $R_{\mathrm{p}}$ & $R_{\text {Bragg }}$ & $R_{\mathrm{F}}$ & $\chi^{2}$ & $a(\AA)$ & $D(\mathrm{~nm})$ & $D_{\mathrm{s}}(\mathrm{nm})$ \\
\hline $\mathrm{Co}_{0.9} \mathrm{Mn}_{0.1} \mathrm{Fe}_{1.8} \mathrm{Mn}_{0.2} \mathrm{O}_{4}$ & 13.7 & 4.89 & 3.59 & 0.79 & $8.374(1)$ & $26(1)$ & 24 \\
$\mathrm{Co}_{0.8} \mathrm{Mn}_{0.2} \mathrm{Fe}_{1.6} \mathrm{Mn}_{0.4} \mathrm{O}_{4}$ & 14.1 & 7.98 & 4.81 & 0.76 & $8.370(1)$ & $22(1)$ & 21 \\
$\mathrm{Co}_{0.7} \mathrm{Mn}_{0.3} \mathrm{Fe}_{1.4} \mathrm{Mn}_{0.6} \mathrm{O}_{4}$ & 13.8 & 8.12 & 6.71 & 1.08 & $8.389(2)$ & $9(1)$ & 10 \\
\hline
\end{tabular}

Errors are given in bracket

where $U, V$ and $W$ are the usual peak shape parameters, IG is a measure of the isotropic size effect, $D_{\mathrm{ST}}=$ coefficient related to strain. The value of the crystallite size of all the samples is listed in Table 2. The size of the crystallite decreases with the increase of $\mathrm{Mn}$ ion concentration. This implies that there might be lattice strain inside the spinel lattice due to size mismatch of host and doped cation, which leads to local structural disorder and reduces the rate of nucleation as an effect decrease the crystallite size. We have observed an enormous decrease in crystallite size for $x=0.3$ samples compared to that in $x=0.2$ samples.

Lattice constants for all the samples are listed in Table 2. The lattice constant decreases with the Mn concentration up to $x=0.2$ composition. The observed decrease is due to difference in ionic radius of host and doped cations. The ionic radius of $\mathrm{Co}^{2+}, \mathrm{Fe}^{3+}, \mathrm{Mn}^{2+}$ are $0.58,0.49$, and $0.66 \AA$, respectively, in tetrahedral geometry, and in octahedral geometry the ionic radius for $\mathrm{Co}^{2+}$, $\mathrm{Fe}^{3+}, \mathrm{Mn}^{2+}$ and $\mathrm{Mn}^{3+}$ are $0.74,0.64,0.83$, and $0.64 \AA$, respectively. For $x=0.3$ composition, there is unusual increase in the lattice constant. It could be due to smaller size of the crystallite for $x=0.3$. The maximum solid solution of $\mathrm{Mn}$ ions in spinel lattice is for $x=0.3$ as we have observed the phase segregation for $x=0.4$. Hence, maximum distortion at the lattice site is expected for $x=0.3$ sample. This prevents the nucleation to grow the crystal, which is discussed in the previous section. One may get bigger size by annealing at higher temperature. However, in the present study, we have kept the preparation conditions same for all samples and obtained very small crystallite size for $x=0.3$ sample annealed at $600^{\circ} \mathrm{C}$ compare to that of $x=0.1$ and 0.2 samples. Therefore, we conclude that the larger lattice parameter for $x=0.3$ sample compare to $x=0.1$ and 0.2 samples due to its smaller size.

The cation distributions in 8-tetrahedral and 16-octahedral interstitial sites were estimated qualitatively by the Rietveld refinement of the occupancy values. Values are qualitative, as we have taken oxygen occupancy as a fixed parameter during fitting. However, oxygen is a lighter element; therefore, it is difficult to refine from XRD data. The estimated cation distribution from the Rietveld analysis is shown in Table 3. The cation distributions show that average particle size determined by FE-SEM $\left(D_{\mathrm{s}}\right)$ for the samples $\mathrm{Co}_{1-x} \mathrm{Mn}_{x} \mathrm{Fe}_{2-2 x} \mathrm{Mn}_{2 x} \mathrm{O}_{4}(x=0.1,0.2$ and 0.3 )
Table 3 Qualitative site occupancies of cations for the samples $\mathrm{Co}_{1-x} \mathrm{Mn}_{x} \mathrm{Fe}_{2-2 x} \mathrm{Mn}_{2 x} \mathrm{O}_{4}(x=0.1,0.2$ and 0.3 )

\begin{tabular}{lll}
\hline Samples & A-site & B-site \\
\hline $\mathrm{Co}_{0.9} \mathrm{Mn}_{0.1} \mathrm{Fe}_{1.8} \mathrm{Mn}_{0.2} \mathrm{O}_{4}$ & $\mathrm{Co}_{0.182} \mathrm{Fe}_{0.760} \mathrm{Mn}_{0.058}$ & $\mathrm{Co}_{0.718} \mathrm{Fe}_{1.040} \mathrm{Mn}_{0.242}$ \\
$\mathrm{Co}_{0.8} \mathrm{Mn}_{0.2} \mathrm{Fe}_{1.6} \mathrm{Mn}_{0.4} \mathrm{O}_{4}$ & $\mathrm{Co}_{0.160} \mathrm{Fe}_{0.745} \mathrm{Mn}_{0.095}$ & $\mathrm{Co}_{0.640} \mathrm{Fe}_{0.855} \mathrm{Mn}_{0.505}$ \\
$\mathrm{Co}_{0.7} \mathrm{Mn}_{0.3} \mathrm{Fe}_{1.4} \mathrm{Mn}_{0.6} \mathrm{O}_{4}$ & $\mathrm{Co}_{0.071} \mathrm{Fe}_{0.812} \mathrm{Mn}_{0.117}$ & $\mathrm{Co}_{0.629} \mathrm{Fe}_{0.588} \mathrm{Mn}_{0.783}$ \\
\hline
\end{tabular}

the structure is in mixed spinel phase as $\mathrm{Co}, \mathrm{Fe}$ and $\mathrm{Mn}$ ion are randomly distributed over interstitial sites. The cation distribution produces a significant effect on the magnetic properties, which is discussed in the next section.

The formation of the spinel structure of the sample in the nanocrystalline form and its cation distribution is supported by FT-IR analysis. The FT-IR spectra of the samples with $x=0.1$ and 0.3 composition are shown in Fig. 3. The spectra indicate the presence of absorption bands in the range of $390-750 \mathrm{~cm}^{-1}$, which is a common feature of the spinel ferrite (Waldron 1955). The higher frequency absorption band $\left(v_{1}\right)$ lies in the range $500-600 \mathrm{~cm}^{-1}$ and, it is assigned to vibration of the tetrahedral metal complex which is the bond between the oxygen ion and the

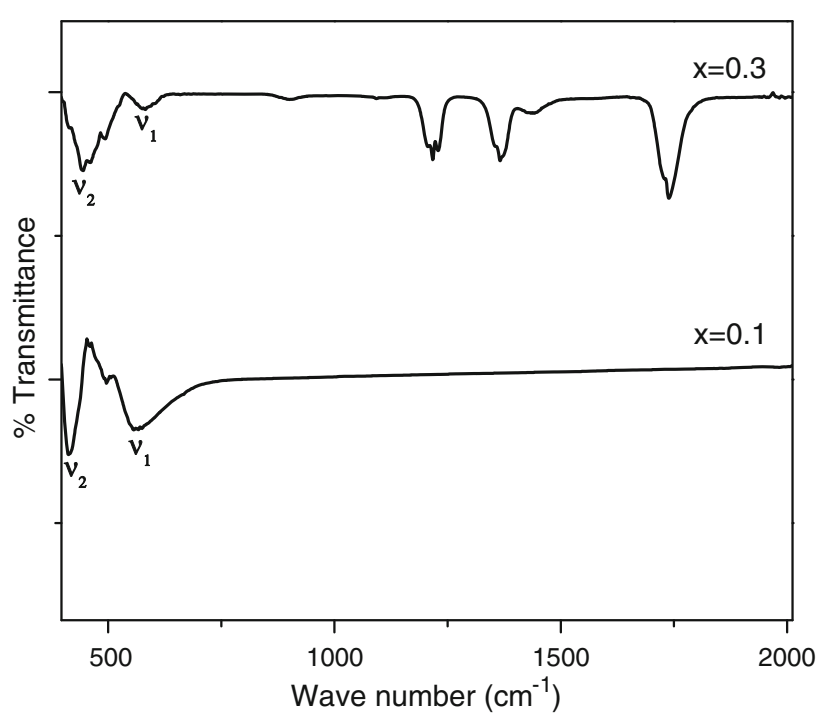

Fig. 3 FT-IR spectra of the samples $\mathrm{Co}_{1-x} \mathrm{Mn}_{x} \mathrm{Fe}_{2-2 x} \mathrm{Mn}_{2 x} \mathrm{O}_{4}$ $(x=0.1$ and 0.3$)$ 


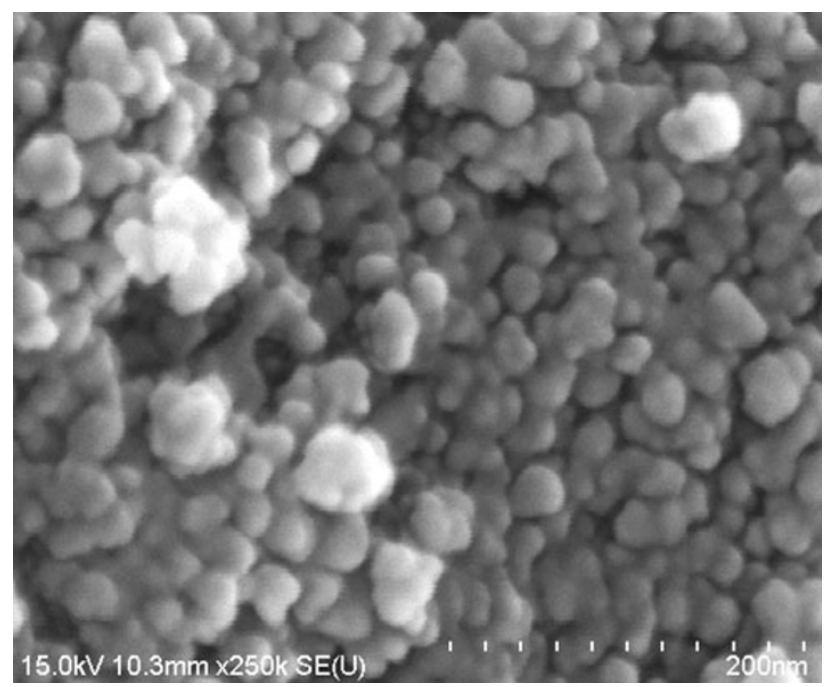

Fig. 4 FE-SEM image of the sample $\mathrm{Co}_{0.9} \mathrm{Mn}_{0.1} \mathrm{Fe}_{1.8} \mathrm{Mn}_{0.2} \mathrm{O}_{4}$ annealed at $600^{\circ} \mathrm{C}$. Average particle size is found to be $28 \mathrm{~nm}$

tetrahedral site metal ion $\left(\mathrm{M}_{\mathrm{Tet}}-\mathrm{O}\right)$. Lower frequency absorption band $\left(v_{2}\right)$ lies in the range of $400-490 \mathrm{~cm}^{-1}$ and, it is assigned to vibration of the octahedral metal complex which is the bond between the oxygen ion and the octahedral site metal ion $\left(\mathrm{M}_{\mathrm{Oct}}-\mathrm{O}\right)$ (Ramankutty and Sugunam 2001). These band positions are found to be in agreement with the characteristic infrared absorption bands of cobalt ferrite nanocrystals (Kamble et al. 2011).

Typical FE-SEM image of the sample $\mathrm{Co}_{0.9} \mathrm{Mn}_{0.1}$ $\mathrm{Fe}_{1.8} \mathrm{Mn}_{0.2} \mathrm{O}_{4}$ is shown in Fig. 4. The image shows that the particles have an almost homogeneous distribution. The average size is found to be $\sim 21 \mathrm{~nm}$, which is close to the crystallite size obtained from XRD patterns. It reveals that samples are in nanometer size. The compositions of samples are determined using the EDS analysis. The typical EDS pattern of sample $\mathrm{Co}_{0.9} \mathrm{Mn}_{0.1} \mathrm{Fe}_{1.8} \mathrm{Mn}_{0.2} \mathrm{O}_{4}$ is shown in Fig. 5. The EDS pattern reveals the presence of $\mathrm{Co}, \mathrm{Fe}, \mathrm{Mn}, \mathrm{Au}$ and $\mathrm{O}$ elements in the sample. One can see that except the extra gold $(\mathrm{Au})$ peak; no any other peaks have been traced. The gold peak appears due to the thin coating on the sample surface to make it conducting. It reveals that there is no contamination in the sample. We have observed that the ratio of the elements is close to the empirical formula.

Magnetic hysteresis loops for $\mathrm{Co}_{1-x} \mathrm{Mn}_{x} \mathrm{Fe}_{2-2 x} \mathrm{Mn}_{2 x} \mathrm{O}_{4}$ $(x=0.1,0.2$ and 0.3) samples are shown in Fig. 6. The values of coercivity for all the samples are listed in Table 4. It is observed that the coercivity decreases with the increase of Mn concentration, which may be described as follows: (i) the size of the crystallite decreases with the increase of Mn concentration. In a single domain region the coercivity decreases with the decrease of crystallite size due to the thermal effects and, its relation with crystallite size is expressed as (Cullity 2009),

$H_{\mathrm{C}}=g-\frac{h}{D^{2}}$

where, $g$ and $h$ are constant. The crystallite sizes of the $\mathrm{Mn}$ substituted samples are within limit of single domain and, hence the coercivity decreases with decrease of crystallite size. (ii) With increasing Mn concentration, the superexchange interaction between the $\mathrm{Fe}$ ions on the $\mathrm{A}$ and $\mathrm{B}$ sites is weakened and becomes uncoupled which facilitates the flipping of the magnetic moment (Goodenough and Loeb 1955; Rath et al. 2000).

The saturation magnetizations $M_{\mathrm{s}}$ for all the samples were estimated from a fit over the high field data using the "Law of Approach to Saturation" equation (discussed in
Fig. 5 EDS pattern of the sample $\mathrm{Co}_{0.9} \mathrm{Mn}_{0.1}$ $\mathrm{Fe}_{1.8} \mathrm{Mn}_{0.2} \mathrm{O}_{4}$

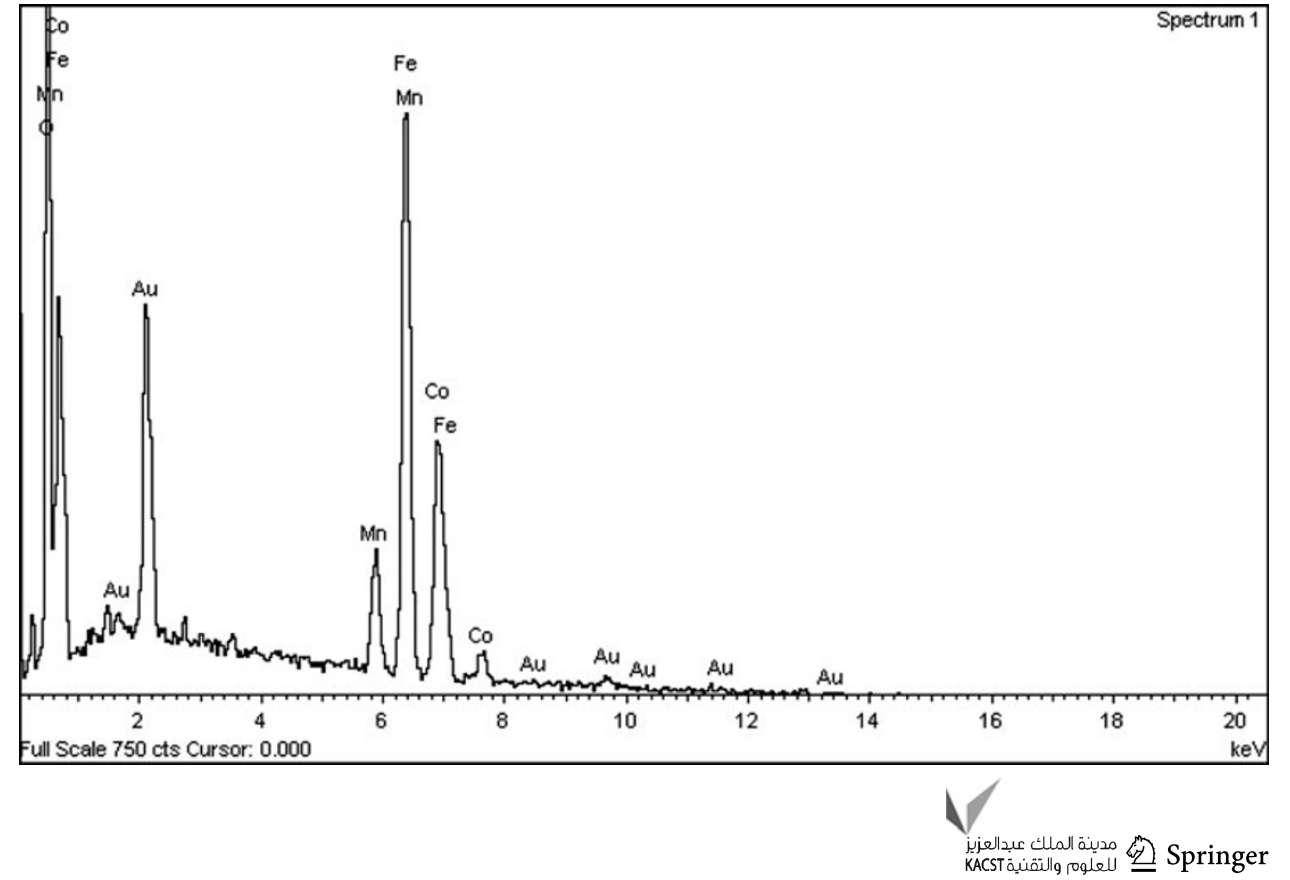




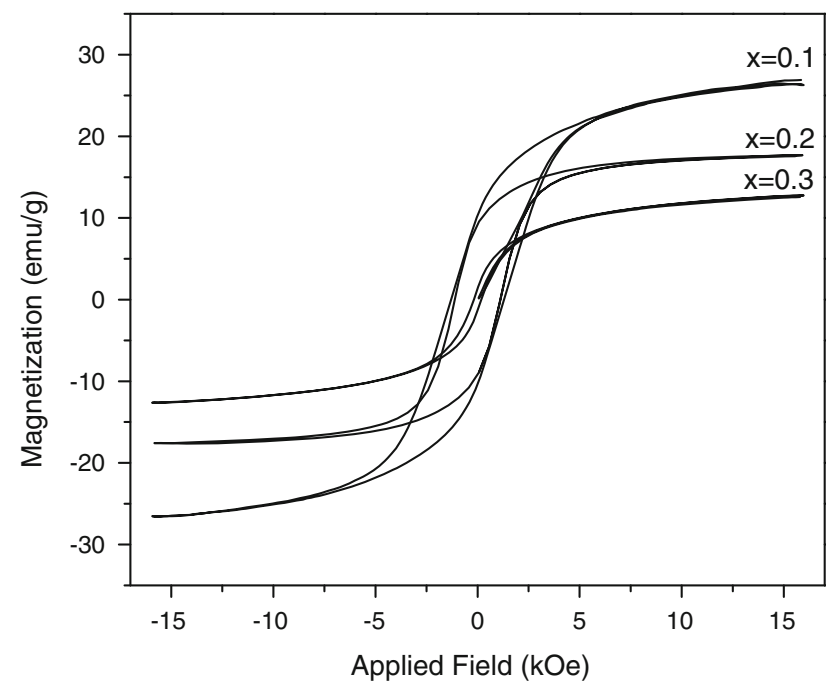

Fig. 6 Magnetic hysteresis loops for samples $\mathrm{Co}_{1-x} \mathrm{Mn}_{x} \mathrm{Fe}_{2-2 x} \mathrm{Mn}_{2 x} \mathrm{O}_{4}$ $(x=0.1,0.2$ and 0.3$)$

the next section) and these values are listed in Table 4 . The saturation magnetization decreases with the increase in $\mathrm{Mn}$ concentration. The saturation magnetization for nanocrystalline spinel ferrite material depends on cation distribution over A and B sites. According to Neel's two sublattice model (Cullity 2009) of collinear ferrimagnetism, the magnetic moment per formula unit is expressed as $M=M_{\mathrm{B}}-M_{\mathrm{A}}$, where $M_{\mathrm{B}}$ and $M_{\mathrm{A}}$ are the magnetic moments at the B-site and A-site, respectively. Cations distribution shows (Table 3) that ions ( $\mathrm{Co}, \mathrm{Mn}$ and $\mathrm{Fe}$ ) are randomly distributed. Occupancy of $\mathrm{Mn}$ ions as $\mathrm{Mn}^{2+}$ $\left(5 \mu_{\beta}\right)$ is more in A-site, which may induce a reduction in net magnetization. In addition, surface effect affects the saturation magnetization $\left(M_{\mathrm{s}}\right)$. External surface structure is distorted and ions are under the effect of strain, which leads to vacancies, varieties of interatomic spacings and low coordination numbers due to the surface effect. All these factors result to broken exchange bond, which leads to spin disorder and exhibit low magnetization (Kodama et al. 1996).

In order to extract the anisotropy information of the samples $\mathrm{Co}_{1-x} \mathrm{Mn}_{x} \mathrm{Fe}_{2-2 x} \mathrm{Mn}_{2 x} \mathrm{O}_{4}$ annealed at $600^{\circ} \mathrm{C}$, the "Law of Approach (LA)" to saturation was employed to analyze the data in saturation region. LA describes the dependence of magnetization $\mathrm{M}$ on the applied magnetic field for $H \gg H_{\mathrm{c}}$. The magnetization near the saturation $M_{\mathrm{s}}$ can be written as (Chikazumi 1997),

$M=M_{\mathrm{S}}\left(1-\frac{b}{H^{2}}\right)$

where $M$ is the magnetization, $H$ is the applied magnetic field, $M_{\mathrm{s}}$ is the saturation magnetization, $\mu_{\mathrm{o}}$ is the permeability of the free space and $K_{1}$ is the cubic anisotropy constant. The numerical coefficient 8/105
Table 4 Parameters obtained from magnetic hysteresis loop measurement at room temperature for the samples $\mathrm{Co}_{1-x} \mathrm{Mn}_{x} \mathrm{Fe}_{2-2 x}$ $\mathrm{Mn}_{2 x} \mathrm{O}_{4}(x=0.1,0.2$ and 0.3$)$

\begin{tabular}{lllr}
\hline Samples & $M_{\mathrm{s}}(\mathrm{emu} / \mathrm{g})$ & $H_{\mathrm{c}}(\mathrm{kOe})$ & $K_{1}\left(\mathrm{erg} / \mathrm{cm}^{3}\right)$ \\
\hline $\mathrm{Co}_{0.9} \mathrm{Mn}_{0.1} \mathrm{Fe}_{1.8} \mathrm{Mn}_{0.2} \mathrm{O}_{4}$ & 26 & 1.252 & $1.41 \times 10^{6}$ \\
$\mathrm{Co}_{0.8} \mathrm{Mn}_{0.2} \mathrm{Fe}_{1.6} \mathrm{Mn}_{0.4} \mathrm{O}_{4}$ & 12 & 1.010 & $0.9 \times 10^{6}$ \\
$\mathrm{Co}_{0.7} \mathrm{Mn}_{0.3} \mathrm{Fe}_{1.4} \mathrm{Mn}_{0.6} \mathrm{O}_{4}$ & 11 & 0.186 & $0.02 \times 10^{6}$
\end{tabular}

$M_{\mathrm{s}}$ saturation magnetization, $H_{\mathrm{c}}$ coercivity, $K_{1}$ magnetocrystalline anisotropy constant

applies to cubic anisotropy of random polycrystalline samples. Therefore, $M_{\mathrm{s}}$ and $K_{1}$ are the only fitting parameters in the Eq. 3. The magnetization data $(M-$ $H$ curve) above than $1 \mathrm{~T}$ (high field parts) is fitted to Eq. 3 . Typical fitting curve to LA is shown in Fig. 7 for the sample $\mathrm{Co}_{0.9} \mathrm{Mn}_{0.1} \mathrm{Fe}_{1.8} \mathrm{Mn}_{0.2} \mathrm{O}_{4}$. The values of $M_{\mathrm{s}}$ and $b$ are obtained from fitting and, magnetocrystalline anisotropy constant $\left(K_{1}\right)$ was calculated using the equation.

$K_{1}=\mu_{\mathrm{o}} M_{\mathrm{S}} \sqrt{105 b / 8}$

The values of magnetocrystalline anisotropy constant for all the samples are listed in Table 4. Our result of magnetocrystalline anisotropy for undoped sample $\left(\mathrm{CoFe}_{2} \mathrm{O}_{4}\right)$ is comparable to the earlier reports on the nanocrystalline cobalt ferrites (Franco and Silva 2010). In bulk form, the magnetocrystalline anisotropy of cobalt ferrite $\left(\mathrm{CoFe}_{2} \mathrm{O}_{4}\right)$ is primarily due to a strong spin (S)-orbit (L) coupling in $\mathrm{Co}^{2+}$ ions at the octahedral sites. The crystal field (trigonal field) is not capable of removing the orbital degeneracy of $\mathrm{Co}^{2+}$ at the octahedral sites. So, the orbital magnetic moment is not quenched and, therefore there is strong spin-orbit coupling ( $\mathrm{L}-\mathrm{S}$ coupling) which produces magnetocrystalline anisotropy (Chikazumi 1997). However, the magnetocrystalline anisotropy $\left(K_{1}\right)$ is

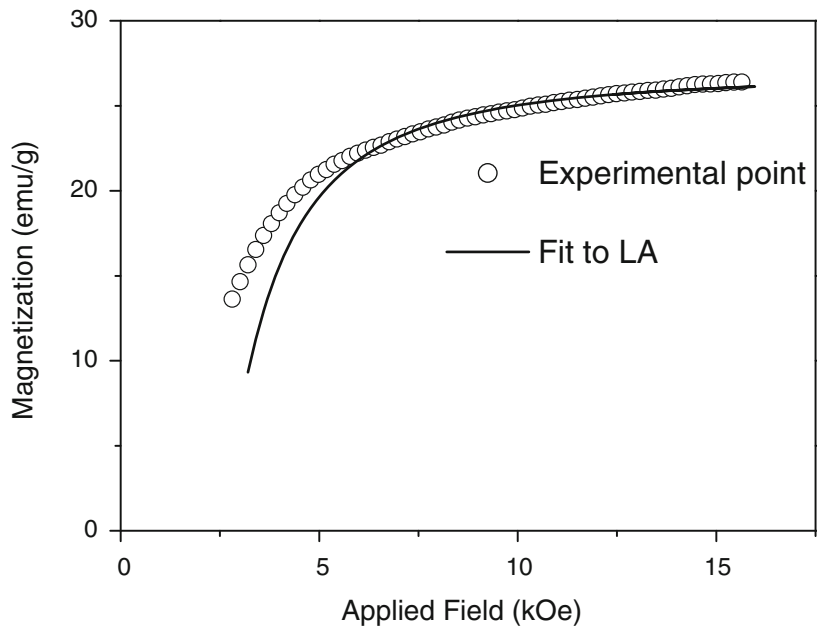

Fig. 7 Fit to LA (Law of Approach) for the sample $\mathrm{Co}_{0.9} \mathrm{Mn}_{0.1} \mathrm{Fe}_{1.8} \mathrm{Mn}_{0.2} \mathrm{O}_{4}$ 
dependent on both spin (S)-orbit (L) coupling as well as on the degree of crystallinity in nanocrystalline form (Chiu et al. 2008). The magnetocrystalline anisotropy constant for the sample decreases with the Mn concentration. The observed behavior may be due to reduction of occupancy of $\mathrm{Co}$ ions at the B-sites, which have been observed from XRD analysis. Another factor such as surface effect may also affect the $K_{1}$. The size of the crystallite decrease with Mn concentration and size reduction leads to large surfaceto-volume atoms. Due to large surface-to-volume atoms, surface strain is dominant at the surface of the samples, i.e., crystal lattice are not in well defined order which may perturb the crystal symmetry at the surface and, hence affects the magnetocrystalline anisotropy.

We have observed the decrease in coercivity, saturation magnetization and magnetocrystalline anisotropy constant with increase in Mn substitution in $\mathrm{CoFe}_{2} \mathrm{O}_{4}$. The obtained results could be used in many potential applications. The present material can be used in high-density recording media, as it exhibits low coercivity and moderate saturation magnetization. For use in high-density recording media, the material must have moderate saturation magnetization, low coercivity and low magnetocrystalline anisotropy constant, i.e., it should show soft magnetic character. The writing and reading heads for high-density recording media are soft, magnetic materials. Heads must be made with very narrow record gaps to record the high densities because the bit length generally scales with the gap. On the other hand, if the gap is made too small, the magnetic core of the head will saturate. Thus, high-density recording heads must be made of materials, which have moderate saturation magnetization. Furthermore, good head materials must have low coercivity. Otherwise, when the write current in the head is turned off, the head will retain a high degree of magnetization. It produces a field, which will disturb the previously written information (Bertram 1994). Moreover, these materials can be used as magnetic sensor (Caltun et al. 2007) and hyperthermia treatment (Georgia 2009), which can be explored by magnetostrictive and localized heating by induction methods, respectively. However, more studies on these materials are required to explore these applications.

\section{Conclusions}

The structural and magnetic properties of nanocrystalline $\mathrm{Co}_{1-x} \mathrm{Mn}_{x} \mathrm{Fe}_{2-2 x} \mathrm{Mn}_{2 x} \mathrm{O}_{4}(x=0.1,0.2,0.3$ and 0.4$)$ samples have been investigated. $\mathrm{Mn}$ is not soluble to crystal lattice beyond 0.3 . The XRD spectrum indicates the formation of the pure spinel phase $(F d \overline{3} m)$ for $x \leq 0.3$ composition. The FT-IR spectra shows absorption bands within the specific frequency limit which supports the formation of the spinel phase. Saturation magnetization, coercivity, and magnetocrystalline anisotropy constant at room temperature $\left(25^{\circ} \mathrm{C}\right)$ show a decreasing trend with increase in $\mathrm{Mn}$ ion concentration in $\mathrm{Co}_{1-x} \mathrm{Mn}_{x} \mathrm{Fe}_{2-2 x}$ $\mathrm{Mn}_{2 x} \mathrm{O}_{4}$. It is due to the size effect as well as modification of superexchange interaction between the cations in the lattice sites. Thus, structural parameters and magnetic behaviors at room temperature in nanocrystalline $\mathrm{Co}_{1-x} \mathrm{Mn}_{x} \mathrm{Fe}_{2-2 x}$ $\mathrm{Mn}_{2 x} \mathrm{O}_{4}$ materials are controllable for $x \leq 0.2$. It shows some unusual behavior for high concentration $(x=0.3)$, which could be due to the strain in the lattice site. The present studies on $\mathrm{Co}_{1-x} \mathrm{Mn}_{x} \mathrm{Fe}_{2-2 x} \mathrm{Mn}_{2 x} \mathrm{O}_{4}$ material suggest that it can be used in high-density recording media.

Acknowledgments The authors gratefully acknowledge Department of Atomic Energy, Government of India (Sanction No. 2011/20/ 37P/03/BRNS/076) for the financial support. Central Instrumentation Facility, IIT, Guwahati, is acknowledged for extending the VSM facility.

Open Access This article is distributed under the terms of the Creative Commons Attribution License which permits any use, distribution, and reproduction in any medium, provided the original author(s) and the source are credited.

\section{References}

Abbas YM, Mansour SA, Ibrahim MH, Ali SE (2011) Microstructure characterization and cation distribution of nanocrystalline cobalt ferrite. J Magn Magn Mater 323:2748-2756. doi:10.1016/j. jmmm.2011.05.038

Bertram HN (1994) Theory of magnetic recording. Cambridge University Press, England

Bhagwat M, Ramaswamy AV, Tyagi AK, Ramaswamy V (2003) Rietveld refinement study of nanocrystalline copper doped zirconia. Mat Res Bull 38:1713-1724. doi:10.1016/S00255408(03)00201-0

Bhowmik RN, Ranganathan R, Sarkar S, Bansal C, Nagarajan R (2003) Magnetic enhancement of $\mathrm{Co}_{0.2} \mathrm{Zn}_{0.8} \mathrm{Fe}_{2} \mathrm{O}_{4}$ spinel oxide by mechanical milling. Phys Rev B 68:134433-134442. doi: 10.1103/PhysRevB.68.134433

Caltun OF, Rao GSN, Rao KH, Rao BP, Kim C, Kim CO, Dumitru I, Lupu N, Chiriac H (2007) High magnetostrictive cobalt ferrite for sensor application. Sens Lett 5:1-3. doi:10.1166/s1.2007.027

Chikazumi S (1997) Physics of ferromagnetism. Oxford University Press, NewYork

Chinnasamy CN, Narayanasamy A, Ponpandian N, Chottopadhyay K, Shinoda K, Jeyadevan B, Tohji K, Nakatsuka K, Furubayashi T, Nakatani I (2001) Mixed spinel structure in nanocrystalline $\mathrm{NiFe}_{2} \mathrm{O}_{4}$. Phys Rev B 63:184108-184114. doi:10.1103/PhysRevB. 63.184108

Chiu WS, Radiman S, Shukor RA, Abdullah MH, Khiew PS (2008) Tunable coercivity of $\mathrm{CoFe}_{2} \mathrm{O}_{4}$ nanoparticles via thermal annealing treatment. J Alloys Compd 459:291-297. doi:10.1016/ j.jallcom.2007.04.215

Cullity BD (2009) Introduction to magnetic materials. Wiley, New Jersey

Dwivedi GD, Tseng KF, Chan CL, Shahi P, Lourembam J, Chatterjee B, Ghosh AK, Yang HD, Chatterjee S (2010) Signature of ferroelectricity in magnetically ordered Mo-doped $\mathrm{CoFe}_{2} \mathrm{O}_{4}$. Phys Rev B 82:134428-134433. doi:10.1103/PhysRevB.82.134428 
Franco AJ, Silva FC (2010) High temperature magnetic properties of cobalt ferrite nanoparticles. Appl Phys Lett 96:172505-172508. doi: $10.1063 / 1.3422478$

Goldman A (2006) Modern ferrite technology. Springer, New York

Goodenough JB, Loeb AL (1955) Theory of ionic ordering, crystal distortion and magnetic exchange due to covalent forces in spinels. Phys Rev 98:391-408. doi:10.1103/PhysRev.98.391

Haneda K, Morrish AH (1988) Non collinear magnetic structure of $\mathrm{CoFe}_{2} \mathrm{O}_{4}$ small particles. J Appl Phys 105:731-738. doi:10.1063/ 1.340197

Jacob J, Khadar MA (2010) Investigation of mixed spinel structure of nanostructured nickel ferrite. J Appl Phys 107:114310-114320. doi:10.1063/1.3429202

Jadhav SS, Shirsath SE, Patange SM, Jadhav KM (2010) Effect of Zn substitution on magnetic properties of nanocrystalline cobalt ferrite. J Appl Phys 108:093920-093926. doi:10.1063/1.3499346

Jovic NG, Masadeh AS, Kremenovic AS, Antic BV, Blanusa JL, Cvjeticanin ND, Goya GF, Antisari MV, Bozin ES (2009) Effect of thermal annealing on structural and magnetic properties of lithium ferrite nanoparticles. J Phys Chem C 113:20559-20567. doi:10.1021/jp907559y

Kambale RC, Shaikh PA, Harale NS, Bilur VA, Kolekar YD, Bhosale $\mathrm{CH}$, Rajpure KY (2010) Structural and magnetic properties of $\mathrm{Co}_{1-x} \mathrm{Mn}_{x} \mathrm{Fe}_{2} \mathrm{O}_{4} \quad(0 \leq x \leq 0.4)$ spinel ferrite synthesized by combustion route. J Alloys Compd 490:568-571. doi:10.1016/ j.jallcom.2009.10.082

Kamble RC, Song KM, Koo YS, Hur N (2011) Low temperature synthesis of nanocrystalline $\mathrm{Dy}^{3+}$ doped cobalt ferrite: structural and magnetic properties. J Appl Phys 110:053910-053917. doi: 10.1063/1.3632987

Kodama RH, Berkowitz AE, Mcniff EJ, Foner S (1996) Surface spin disorder in $\mathrm{NiFe}_{2} \mathrm{O}_{4}$ nanoparticles. Phys Rev Lett 77:394-397. doi:10.1103/PhysRevLett.77.394

Kumar L, Kar M (2011a) Effect of annealing temperature and preparation condition on magnetic anisotropy in nanocrystalline cobalt ferrite. IEEE Trans Magn 47:3645-3648. doi:10.1109/ TMAG.2011.2151841

Kumar L, Kar M (2011b) Influence of $\mathrm{Al}^{3+}$ ion concentration on the crystal structure and magnetic anisotropy of nanocrystalline spinel cobalt ferrite. J Mag Mag Mater 323:2042-2048. doi: 10.1016/j.jmmm.2011.03.010

Lu ZM, Li ZW, Shen J, Meng FB, Liu HY, Li YX, Li CY (2009) Magnetic and structural properties of $\mathrm{Co}_{0.8} \mathrm{Mn}_{x} \mathrm{Fe}_{2.2-x} \mathrm{O}_{4}$ $(x=0.2,0.4,0.6,0.8)$ polycrystalline powders synthesized by sol-gel process. J Appl Phys 105:07A519-07A521. doi:10.1063/ 1.3072441

Molikhov Y, Snyder JE, Jiles DC, Ring AP, Paulsen JA, Lo CCH, Dennis KW (2006) Temperature dependence of magnetic anisotropy in Mn-substituted cobalt ferrite. J Appl Phys 99:08R102-08R105. doi:10.1063/1.2151793

Papaefthymiou GC (2009) Nanoparticle magnetism. Nano Today 4:438-447. doi:10.1016/j.nantod.2009.08.06

Ramankutty CG, Sugunam S (2001) Surface properties and catalytic activity of ferrospinels of nickel, cobalt and copper prepared by soft chemical method. Appl Catal A Gen 39:128-132. doi: 10.1016/S0926-860X(01)00610-X

Rath C, Mishra NC, Anand S, Das RP, Sahu KK, Upadhyay C, Verma $\mathrm{HC}$ (2000) Appearance of superparamagnetism on heating nanosize $\mathrm{Mn}_{0.65} \mathrm{Zn}_{0.35} \mathrm{Fe}_{2} \mathrm{O}_{4}$. Appl Phys Lett 76:475-478. doi: $10.1063 / 1.125792$

Shobana MK, Sankar S (2009) Characterization of sol gel prepared nanoferrites. J Mag Mag Mater 321:599-601. doi:10.1016/j. jmmm.2008.09.040

Valenzuela R (1994) Magnetic ceramics. Cambridge University Press, UK

Waldron RD (1955) Infrared spectra of ferrites. Phys Rev 99:1727-1729. doi:10.1103/PhysRev.99.1727

Young RY (1996) The Rietveld method. Oxford University Press, Oxford 